\title{
MicroRNAs Regulate Key Effector Pathways of Senescence
}

\author{
Andrea Feliciano, ${ }^{1}$ Beatriz Sánchez-Sendra, ${ }^{1}$ Hiroshi Kondoh, ${ }^{2}$ and Matilde E. LLeonart ${ }^{1}$ \\ ${ }^{1}$ Oncology and Molecular Pathology Group, Pathology Department, Fundacil Institut de Recerca Hospital Vall d'Hebron, \\ Passeig Vall d'Hebron 119-129, 08035 Barcelona, Spain \\ ${ }^{2}$ Department of Geriatric Medicine, Graduate School of Medicine, Kyoto University, 54 Kawahara-cho, Shogoin, \\ Sakyo-ku, Kyoto 606-8507, Japan \\ Correspondence should be addressed to Matilde E. LLeonart, melleona@ir.vhebron.net
}

Received 7 February 2011; Accepted 9 March 2011

Academic Editor: Amancio Carnero

Copyright (c) 2011 Andrea Feliciano et al. This is an open access article distributed under the Creative Commons Attribution License, which permits unrestricted use, distribution, and reproduction in any medium, provided the original work is properly cited.

\begin{abstract}
MicroRNAs (miRNAs) are small (approximately $22 \mathrm{nt}$ ) noncoding endogenous RNA molecules that regulate gene expression and protein coding by base pairing with the $3^{\prime}$ untranslated region (UTR) of target mRNAs. miRNA expression is associated with cancer pathogenesis because miRNAs are intimately linked to cancer development. Senescence blocks cell proliferation, representing an important barrier that cells must bypass to reach malignancy. Importantly, certain miRNAs have been shown to have an important role during cellular senescence, which is also involved in human tumorigenesis. Therefore, therapeutic induction of senescence by drugs or miRNA-based therapies is a potential method to treat cancer by inducing a persistent growth arrest in tumors.
\end{abstract}

\section{Introduction}

miRNAs are small noncoding RNAs (approximately $22 \mathrm{nt}$ ) that regulate gene expression by interfering with protein translational machinery and/or inducing degradation of target mRNAs [1]. Hundreds of microRNA (miRNA) genes have been found in animals, plants, and viruses [2-4] making them one of the largest gene families.

Recent studies revealed the key roles of miRNAs in diverse regulatory pathways including development timing control, hematopoietic cell differentiation, apoptosis, cell proliferation, and organ development [2]. miRNAs and their targets constitute remarkably complex regulatory networks because a single miRNA can bind to and regulate many different mRNA targets, and conversely, several different miRNAs can bind to and cooperatively control a single mRNA target [5]. In general, miRNAs repress protein expression at the posttranscriptional level through base pairing with the $3^{\prime}$-UTR leading to reduced translation, or in some cases, degradation. However, some miRNAs have been shown to bind to the open reading frame or to the $5^{\prime}$-UTR of the target mRNAs. In some cases, miRNAs have been shown to activate rather than inhibit gene expression [6-8].
miRNAs are involved in many aspects of cell biology including physiological modulation and pathological disruption of basic pathways. In this regard, miRNAs are key mediators in cancer where they regulate many aspects of tumorigenesis and tumor progression from the initiating steps to metastasis formation and chemosensitivity $[9,10]$. Therefore, miRNA expression may be deregulated in cancer because abnormal miRNA activity may lead to tumorigenesis. It has been shown that human tumors exhibit distinctive miRNA expression signatures [11]. miRNA expression is tissue specific, and certain cancer histotypes can be classified based on miRNA expression profiles [12]. Some miRNAs have been found to be upregulated or downregulated in cancer. An overexpressed miRNA that downregulates a tumor suppressor gene is defined as an oncomir, and a downregulated miRNA that normally downregulates the expression of an oncogene is defined as a tumor suppressor miR (TS-miR). However, some miRNAs may function as oncogenes in some cell types and as tumor suppressors in other cell types [13]. Aberrant miRNA expression in cancer due to chromosomal abnormalities, polymorphism, and/or epigenetic changes has a direct impact on miRNA biogenesis. In this study, we reviewed the potential impact of miRNAs in senescence and cancer. We suggest that the biological 
function of miRNAs is extensively studied in the near future to identify their potential clinical applications.

\section{MicroRNA Biogenesis}

miRNA biogenesis has been studied by many scientists. A schematic overview of miRNA biogenesis is shown in Figure 1. Most of the miRNA genes exist in clusters in the genome and are polycistronically expressed from their own promoter. Other miRNA genes are found in intronic regions and are transcribed as a part of annotated genes. The transcription of most miRNA genes is mediated by RNA polymerase II (Pol II), producing long primary miRNAs (primiRNAs) that are capped at the $5^{\prime}$ end and polyadenylated at the $3^{\prime}$ end. These pri-miRNAs contain a stem of approximately 33 base pairs, a terminal loop, and flanking ssRNA segments [14]. However, a small group of miRNAs associated with Alu repeats can be transcribed by Pol III [15]. Two steps of ribonuclease pro-cessing reactions are required to generate mature miRNAs. The first step occurs in the nucleus and involves the release of a $70 \mathrm{nt}$ intermediate hairpin structure (pre-miRNA) from the RNA duplex in the pri-miRNA by the RNase III-type protein, Drosha [16]. Moreover, Drosha-mediated pri-miRNA processing requires the cofactor, DiGeorge syndrome critical region gene 8 (DGCR8). Together with DGCR8, Drosha forms a large complex known as the microprocessor complex, which is approximately $650 \mathrm{kDa}$ in humans $[17,18]$. Specifically, DGCR8 interacts with pri-miRNAs through the ssRNA segments and the stem (approximately $33 \mathrm{bp}$ ), and DGCR8 assists Drosha to cleave the substrate (approximately $11 \mathrm{bp}$ ) from the ssRNA/dsRNA junction $[19,20]$. The resulting pre-miRNA is transported out of the nucleus and into the cytoplasm by Exportin-5 and its cofactor, Ran-GTP [21].

Apart from the canonical miRNA pathway, an alternative nuclear pathway for miRNA biogenesis has been recently described in invertebrates [22, 23] and mammals [24]. This noncanonical pathway involves short introns with hairpin potential, which are termed mirtrons. Mirtrons bypass are processed by the microprocessor. Therefore, they are processed by splicing and debranching. Debranched mirtrons access the canonical miRNA pathway during nuclear export. The debranched mirtrons are cleaved by Dicer and incorporated into silencing complexes [22,23].

The miRNA maturation process in the cytoplasm is carried out by Dicer, which is a highly conserved RNase III-type endoribonuclease present in almost all eukaryotic organisms. PremiRNAs are cleaved near the terminal loop by Dicer-releasing miRNA duplexes (approximately $22 \mathrm{nt}$ ) [25]. Human Dicer interacts with proteins, such as TAR RNA binding protein (TRBP; also known as TARBP2) [26, 27]. However, current studies have, suggested that they are not required for miRNA processing but that they contribute to the formation of the RNA-induced silencing complex (RISC) [28]. Following Dicer cleavage, the 22-nt RNA duplex binds to Argonaute (Ago) proteins to generate the effector complex, RISC. One strand of the 22-nt RNA duplex remains in the Ago complex as a mature miRNA (the guide strand or miRNA), and the other strand (the passenger strand or miRNA*) is degraded [25]. Next, the miRNA guides RISC to specifically recognize and repress target mRNAs. In most cases, miRNAs repress protein expression through base pairing with the $3^{\prime}$-UTRs of the target mRNA [28]. Perfect complementarity, which is rare in animal miRNA/mRNA base pairing, allows Ago-catalyzed cleavage of the mRNA strand. In contrast, central mismatches exclude cleavage and promote repression of mRNA translation.

The specificity of miRNA targeting is defined by WatsonCrick complementarities between positions 2 to 8 from the $5^{\prime}$-miRNA (also known as the seed) with the $3^{\prime}$-UTR of the target mRNAs. When miRNAs and their target mRNA sequence have perfect complementarities, RISC induces mRNA degradation. When an imperfect miRNA/mRNA target pairing occurs, protein translation is blocked. Regardless which of these two events occurs, the net result is a decrease in the amount of proteins encoded by the mRNA targets.

\section{3. miRNAs Involved in Senescence}

Cellular senescence was originally described in primary cells as a process that limits the replicative potential of human diploid fibroblasts in culture. This type of senescence is called replicative senescence. Senescence is an important block to cell cycle progression during the aging of cells in culture and is a fundamental barrier that cells must bypass during carcinogenesis. Senescent cells are characterized by the expression of $\beta$-galactosidase, overexpression of plasminogen activator protein 1 (PAI-1), and altered cell morphology characterized by a giant cell size, increased cytoplasmic granularity, and a single large nucleus [29].

Cellular senescence is a process that is triggered by several types of stresses as follows: telomeric erosion resulting from repeated cell division (replicative senescence); DNA damage; oxidative stress resulting from mitochondrial deterioration; overexpression of oncogenes; loss of tumor suppressors such as PTEN and VHL (oncogene-induced senescence; OIS) $[29,30]$. OIS was first observed when an oncogenic form of Ras (e.g., Ras ${ }^{\mathrm{G} 12 \mathrm{~V}}$ ), which is a cytoplasmic transducer of mitogenic signals, was expressed in normal human fibroblasts [31]. Other members of the Ras signaling pathway, such as v-raf-1 murine leukemia viral oncogene homolog 1 (RAF), mitogen-activated protein kinase kinase 1 (MEK), $\mathrm{v}$-mos Moloney murine sarcoma viral oncogene homolog (MOS), and v-raf murine sarcoma viral oncogene homolog B1 (BRAF), in addition to pro-proliferative nuclear proteins, such as the E2F transcription factor, can also induce a senescence response upon overexpression [32]. Moreover, OIS can be caused by the loss of the tumor suppressors that function upstream of oncogenes, such as phosphatase and tensin homolog (PTEN), von Hippel-Lindau tumor suppressor (VHL), and neurofibromin 1 (NF1), resulting in an increase of oncogenic signaling that leads to senescence [30]. In general terms, OIS has similar characteristics to replicative senescence including the presence of $\beta$-galactosidase-positive cells, induction of cell cycle inhibitory proteins, and phenotypic morphology of giant cells.

The major pathways that regulate cellular senescence are the $\mathrm{p} 53 / \mathrm{p} 21^{\mathrm{Cip} 1}$ and $\mathrm{p} 16^{\mathrm{INK} 4 \mathrm{~A}}-\mathrm{pRB}$ tumor suppressor 


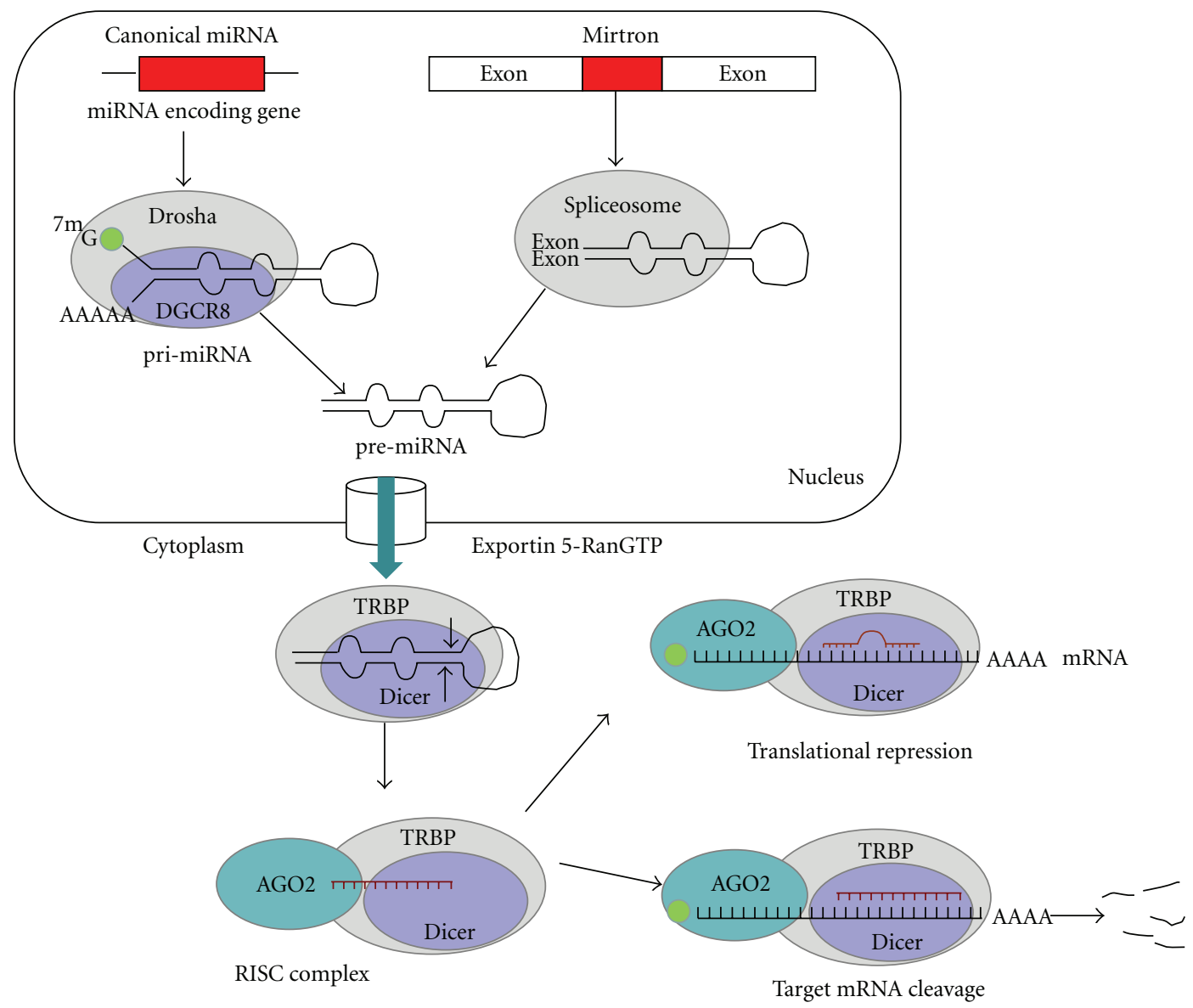

FIGURE 1: miRNA biogenesis. In the nucleus, canonical miRNAs are processed by the endoribonuclease, Drosha, in partnership with DGCR8. In contrast, mirtrons are processed by the spliceosome. The pre-miRNA is then exported from the nucleus into the cytoplasm by Exportin-5, and it is processed into a mature miRNA by Dicer. After RISC incorporation, mature miRNAs inhibit translation or promote degradation of their target mRNA transcripts depending on the degree of complementarity between the $3^{\prime}$-UTR of the target mRNA and the seed region of the miRNA.

pathways. p53 provokes growth arrest, in part by inducing the expression of $\mathrm{p} 21^{\mathrm{Cip} 1}$, which is a cyclin-dependent kinase $(\mathrm{CDK})$ inhibitor that suppresses the phosphorylation and, hence, the inactivation of $\mathrm{pRB}[32,33]$. In addition, senescence signals that engage the $\mathrm{p} 16^{\mathrm{INK} 4 \mathrm{~A}}-\mathrm{pRB}$ pathway generally do so by inducing the expression of $\mathrm{p} 16^{\mathrm{INK} 4 \mathrm{~A}}$, which is another $\mathrm{CDK}$ inhibitor that prevents $\mathrm{pRB}$ phosphorylation and inactivation [32]. In this regard, the loss of tumor suppressors that function downstream of oncogenes, such as p53, impair senescence and allow progression to malignant stages providing a link between tumor suppression and the induction of senescence by $\mathrm{p} 16^{\mathrm{INK} 4 \mathrm{~A}}, \mathrm{p} 19^{\mathrm{ARF}}$, and $\mathrm{p} 53$ [30]. In general, oncogenes that elicit a senescence response often converge on the activation of p53 and/or pRB. However, RAF-induced senescence independent of both p53 and pRB has been reported in human cells [34].

Importantly, several groups have shown that benign tumors contain senescent cells and that these cells fully disappear in the corresponding malignant areas of the patients. Senescent cells are found in premalignant lesions in mice and humans, and they are absent in their corresponding malignant stages, which suggests a role for senescence as a barrier to tumor progression $[35,36]$. In addition, senescent cells are relatively rare in young organisms, but their number increases with age. Consistent with a role in aging, senescent cells accumulate with age in many rodent, primate, and human tissues $[37,38]$. Moreover, they are found at sites of age-related pathology including degenerative disorders, such as osteoarthritis and atherosclerosis [37], in addition to hyperproliferative lesions, such as benign prostatic hyperplasia [39].

Several miRNAs have been reported to be differentially expressed in senescent cells when compared to primary cells, providing a role for miRNAs in senescence (Figure 2, Table 1). Recently, it has been reported that miR-34a overexpression during senescence can be p53 dependent and p53 independent [40-44]. p53 activates transcription of a set of genes, which induces cell cycle arrest, senescence, or apoptosis. Moreover, p53 also regulates the expression of miR-34a because genes in the family of miR-34 genes contain p53binding sites in their promoters, which are conserved among humans and rodents. In turn, miR-34a increases the activity of p53 by means of reducing expression of sirtuin 1 (SIRT1), which interacts with $\mathrm{p} 53$ and deacetylates the Lys382 residue 


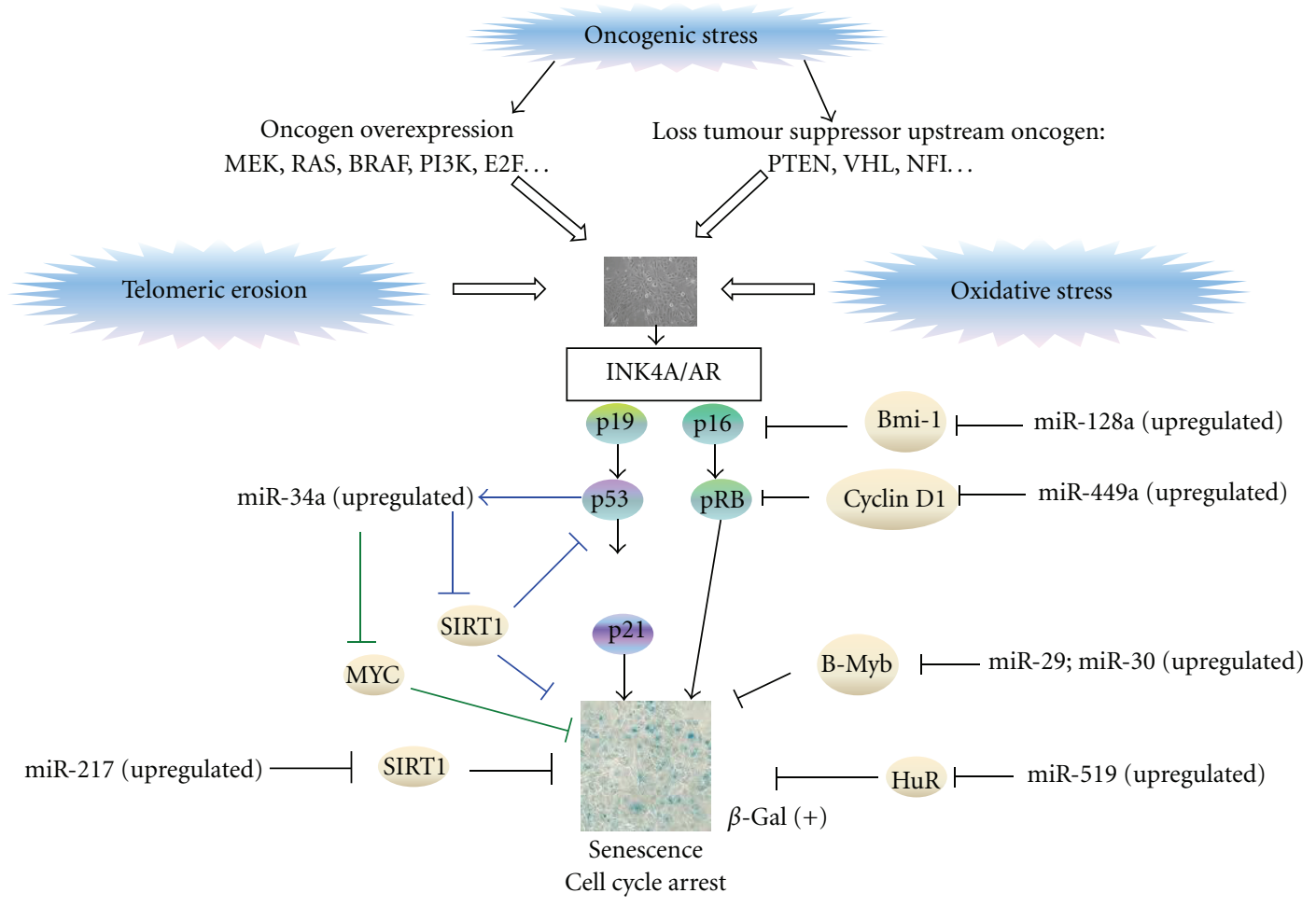

FIGURE 2: Role of miRNAs in senescence. Cellular senescence is triggered by several factors including telomeric erosion, oncogenic stress, oxidative stress, and miRNA modulation. The following miRNAs are key regulatory miRNAs modulating senescence: miR-128a, miR-449a, miR-29, miR-30, miR-519, miR-217, and miR-34a.

of p53 in a $\mathrm{NAD}^{+}$-dependent manner, thereby decreasing p53-mediated transcriptional activation and reducing the expression levels of downstream proteins, such as $\mathrm{p} 21^{\mathrm{Cip} 1}$. Therefore, overexpression of miR-34a decreases SIRT1 expression, allowing an increase in p53 acetylation and p53 activity and thus mediating the senescence response $[43,45]$. On the other hand, several studies have shown that miR34 a causes senescence in a p53-independent manner. miR34a induces senescence and suppression of cell proliferation through downregulation of the E2F pathway in human colon cancer cells p53 $(+/+)$ leading to the upregulation of the $\mathrm{p} 53 / \mathrm{p} 21^{\mathrm{Cip} 1}$ pathway, but also in human colon cancer cells p53 (-/-) [42]. In addition, another study has reported a strong upregulation of miR-34a during B-RAF-induced senescence independent of p53. In this case, miR-34a is transcriptionally upregulated by ELK1, which is a member of the ETS oncogene family and has previously been implicated in cellular senescence. Moreover, miR-34a is upregulated after activation of the B-RAF oncogene. Finally, miR-34a provokes senescence through repression of $\mathrm{v}$-myc myelocytomatosis viral oncogene homolog (Myc) [44]. Importantly, miR-34a, which is a tumor suppressor in the miR-34 family, is downregulated in pancreatic cancer cells, neuroblastomas, colon cancer cells, and lung cancer cells $[40-42,46]$.

The expression levels of miR-29 and miR-30 increase during cellular senescence in a Rb-dependent manner. Moreover, these microRNAs directly repress v-myb myeloblastosis viral oncogene homolog (avian)-like 2 (B-Myb) by binding
TABLE 1: Novel miRNAs involved in senescence.

\begin{tabular}{llc}
\hline miRNA & miRNA function & Reference \\
\hline hsa-miR-29/30 & Oncomir/Tumour suppressor & {$[47-51]$} \\
hsa-miR-34a & Tumour suppressor & {$[40-44]$} \\
hsa-miR-519 & Tumour suppressor & {$[52]$} \\
hsa-miR-449a & Tumour suppressor & {$[53,54]$} \\
hsa-miR-128a & Tumour suppressor & {$[55-57]$} \\
hsa-miR-217 & Tumour suppressor & {$[58,59]$} \\
hsa-miR-372/373 & Oncomir & {$[60-63]$} \\
hsa-miR-17-5p & Oncomir & {$[60,64-69]$} \\
hsa-miR-130b & Oncomir & {$[60,70]$} \\
hsa-miR-15b/25/141 & Oncomir & {$[71-74]$} \\
mmu-miR-20a & Tumour suppressor & {$[75]$} \\
mmu-miR-290 & Tumour suppressor & {$[76]$} \\
\hline
\end{tabular}

to its $3^{\prime}$-UTR acting in conjunction with Rb-E2F complexes at the $\mathrm{B}-\mathrm{Myb}$ promoter to mediate repression of $\mathrm{B}-\mathrm{Myb}$ expression during $\mathrm{Rb}$ activation resulting in senescence [47]. miR-29 is downregulated in mantle cell lymphomas [48], and the overexpression of miR-29 is suppressed during tumorigenicity in lung cancer cells [49]. Moreover, miR-29 is upregulated in indolent human B-cell chronic lymphocytic leukemia (B-CLL) when compared to aggressive B-CLL and normal CD19+ B-cells, suggesting that miR-29 can function as an oncogene and contribute to the pathogenesis 
of indolent CLL. In contrast, miR-29 is downregulated in aggressive CLL when compared to indolent CLL, and miR-29 may function as a tumor suppressor in CLL by targeting Tcell leukemia/lymphoma 1 (TCL-1) [50]. In addition, miR30 directly represses LIN28 (a lin-28 homolog of C. elegans) in embryonic stem cells and cancer cells. Importantly, LIN28 functions as an oncogene promoting malignant transformation and tumor progression [51]. Another miRNA involved in senescence is miR-449a. miR-449a induces senescence by suppressing $\mathrm{Rb}$ phosphorylation by directly repressing the upstream regulatory factors of $\mathrm{Rb}$, such as cyclin D1 (CCND1) [53], histone deacetylase 1 (HDAC1) [53], cyclindependent kinase 6 (CDK6), and cell division cycle 25 homolog A (CDC25A) [54]. A recent study has shown that miR-449a is downregulated in prostate cancer, indicating that this miRNA regulates cell growth and viability, in part by repressing the expression of HDAC-1 [53].

The functional role of miR-128a in senescence is also evident. miR-128a directly targets the Bmi-1 oncogene (polycomb ring finger oncogene; BMI1), increasing p16 $6^{\mathrm{NK} 4 \mathrm{~A}}$ expression and reactive oxygen species (ROS), which promote cellular senescence in medulloblastoma cell lines [55]. Recently, it has been reported that this tumor suppressive miRNA (miR-128a) is downregulated in medulloblastomas [55], glioblastomas [56], and acute myeloid leukemia [57], suggesting that this miRNA has an important role in these types of cancer.

miR-217, which is expressed in endothelial cells during aging, promotes premature senescence by inhibiting SIRT1 expression, thus increasing forkhead box O1 (FoxO1) expression and endothelial nitric oxide synthase (eNOS) acetylation [58]. In addition, miR-217 has been reported to be a novel tumor suppressive miRNA in pancreatic ductal adenocarcinoma due to decreases in tumor cell growth both in vitro and in vivo by targeting K-Ras [59].

miR-290 also acts as a physiological effector of senescence in murine cells including mouse embryonic fibroblasts (MEFs) [76], and miR-20a induces senescence in MEFs through the direct downregulation of the transcriptional regulator leukemia/lymphoma-related factor (LRF), leading to an induction of $\mathrm{p} 19^{\mathrm{ARF}}$ [75]. In addition, miR-519 is another miRNA that induces senescence in cancer cell lines. miR-519 elicits these actions by repressing HuR expression [52]. On the other hand, there are miRNAs that are downregulated during senescence, such as miR-15b, miR24, miR-25, and miR-141, which directly target mitogenactivated protein kinase kinase (MKK4) [71].

Importantly, the escape from OIS is a requirement for transformation into tumor cells. Therefore, high-throughput genomic and miRNA screens have been preformed to identify novel mediators of OIS in human mammary epithelial cells (HMECs), which contain OHT-inducible Ras ${ }^{\mathrm{G} 12 \mathrm{~V}}[60]$. Borgdorff and colleagues showed that 28 miRNAs prevented senescence upon Ras ${ }^{\mathrm{G} 12 \mathrm{~V}}$ induction. These miRNAs are as follows: miR-17-5p, miR-20a-b, miR-93, miR-106a-b, miR130b, miR-302a-d, miR-372, miR-373, miR-512-3p, miR515-3p, miR-519c-e, miR-520a-g, miR-526b*, and miR146a-b. These miRNAs bypass Ras ${ }^{\mathrm{G} 12 \mathrm{~V}}$-induced senescence by directly targeting the $3^{\prime}$-UTR of $\mathrm{p} 21^{\mathrm{Cipl}}$. Moreover,
miR-372, miR-373, miR-302, and miR-520 can also bypass $\operatorname{Ras}^{\mathrm{G} 12 \mathrm{~V}}$-induced senescence through the downregulation of LATS2 in addition to p2 $1^{\mathrm{Cip} 1}$ [60-63]. miR-372 and miR-373 also prevent Ras-induced senescence in human fibroblasts [61], suggesting that the immortalization mechanism of these miRNAs is universal. Importantly, these identified proliferative miRNAs have been demonstrated to be associated with cancer development. For example, miR-17-5p is overexpressed in pancreatic cancer [64], squamous cell carcinoma [65], breast cancer [66], hepatocellular cancer [67], renal cell carcinoma [68], and thyroid cancer [69], suggesting a potential oncogenic role of miR-17-5p. Furthermore, miR$130 \mathrm{~b}$ promotes gastric cancer by downregulating the tumor suppressor, runt-related transcription factor 3 (RUNX3) [70]. In addition, miR-372 and miR-373 have been found to be upregulated in testicular germ cell tumors [61]. Finally, miR-302 is expressed specifically in embryonic stem cells and embryonic carcinoma cells $[77,78]$, suggesting a possible role of this miRNA in cancer stem cell biology.

\section{Senescence Induction Based upon miRNA Modulation as a Therapeutic Approach}

It is well known that the overexpression of several oncogenes (e.g., $\mathrm{Ras}^{\mathrm{G} 12 \mathrm{~V}}$ ) or tumor suppressor genes (e.g., ribosomal protein S6 kinase, $90 \mathrm{kDa}$, polypeptide 6; RSK4) [79] induces senescence. However, cancer cells can be induced to a senescent state with conventional anticancer treatments such as Doxorubicin $[80,81]$. The use of senescence as a novel modality of cancer therapy has been considered in clinical trials with promising results [81].

Senescence may promote carcinogenesis in surrounding tissues [82] by secreting interleukins, chemokines, growth factors, and proteases, which stimulate malignant phenotypes in neighboring cells. In this regard, miR-146a and miR-146b have been demonstrated to negatively regulate the senescence-associated secretion of IL- 6 and IL- 8 by directly targeting IRAK1 and reducing NF- $\kappa$ B activity [83]. Therefore, these miRNAs may be promising tools to restore the protective potential against development of the senescenceassociated secretory phenotype (SASP).

The rationale for using miRNAs as novel anticancer molecules is based on the following two major findings: (1) miRNA expression is deregulated in cancer when compared with normal tissues; (2) the cancer phenotype can be changed by targeting miRNA expression [13].

The therapeutic application of miRNAs involves two major strategies. For oncogenic miRNAs (oncomirs), which promote proliferation when overexpressed, the major therapeutic strategy is directed toward reducing oncomir expression. These therapies include anti-miRNA oligonucleotides, microRNA sponges, miRNA masking, and small molecule inhibitors. For TS-miRs, the therapeutic strategy is directed toward restoring the levels of TS-miRs by exogenous expression (Figure 3).

4.1. Anti-miRNA Oligonucleotides. The base pair interaction between miRNAs and mRNAs is essential for the function of 


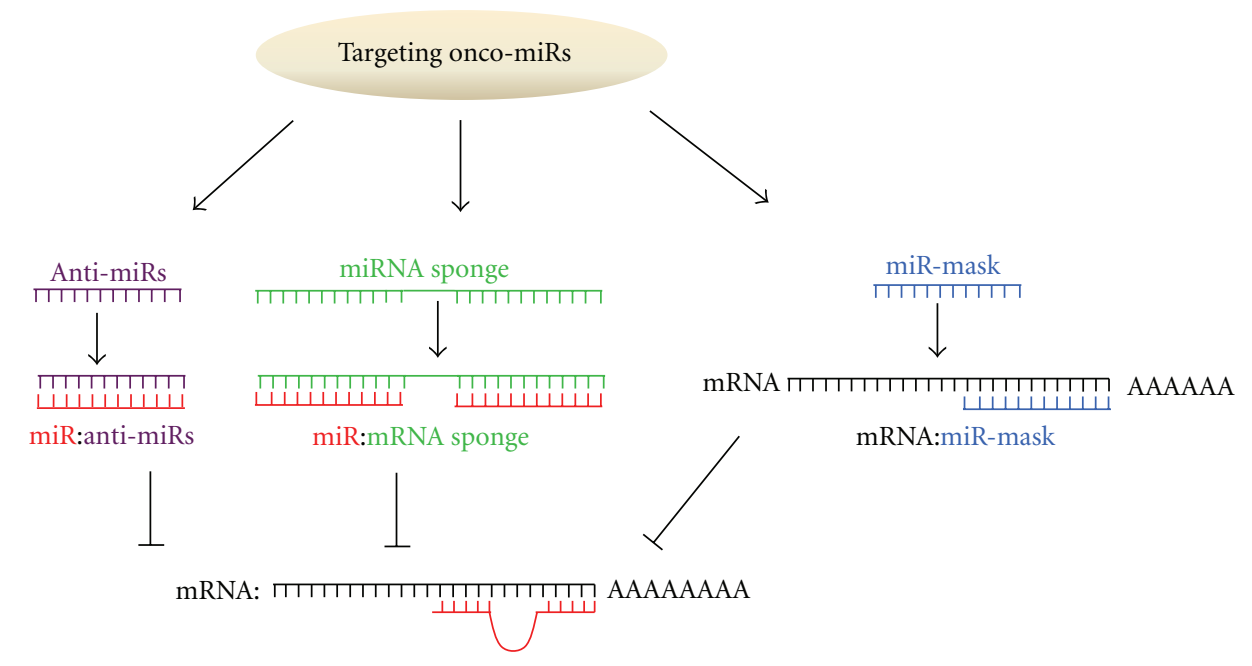

FIGURE 3: miRNA-based molecular cancer therapy for oncogenic miRNAs. The cancer therapies include anti-miRNA oligonucleotides (antimiRs), miRNA sponges, and miRNA masking.

miRNAs. Therefore, a logical approach of silencing miRNAs is to use a nucleic acid that is antisense to the miRNA $[84,85]$. These anti-miRNA oligonucleotides (AMOs) block the interactions between miRNAs and their target mRNAs by competition. Thus, the anti-miRNA oligonucleotides knockdown the oncogenic properties of the miRNA resulting in cancer suppression and decreased cancer progression. Studies targeting miR-21 represent one of the first examples of inhibiting cancer development by downregulating an oncogenic miRNA. miR-21 is overexpressed in most tumor types and acts by targeting many tumor suppressor genes related to proliferation, apoptosis, and invasion including the following genes: programmed cell death 4 (PDCD4) [86-88]; tropomyosin 1 (Tpm1) [89]; PTEN [90, 91]; ras homolog gene family, member $\mathrm{B}$ (RHOB) [92]; polymerase (DNA-directed), delta 4 (POLD4) [93]. Si and colleagues have knocked down miR-21 expression using an anti-miR-21 oligonucleotide transfected into MCF-7 breast cancer cells, and they demonstrated that the anti-miR-21 oligonucleotide suppressed both cell growth and tumor growth in a xenograft mouse model by increasing apoptosis and decreasing cell proliferation [94].

A modified AMO approach has recently been described in which multiple antisense units are engineered into a single unit that is able to simultaneously silence multiple miRNAs. For example, the multiple-target AMO targeting miR-21, miR-155, and miR- 17-5p has a greater inhibitory effect on cell growth in MCF-7 cells when compared to singletarget AMOs or a combination of these single-target AMOs [95]. The multiple-target AMO approach may have a broad application in human tumors.

4.2. miRNA Sponges. miRNA sponges are transcripts that contain multiple tandem-binding sites to a miRNA of interest, therefore preventing the interaction between the miRNA and its endogenous targets. Ebert et al. (2007) [96] engineered such molecules by inserting a bulge between the
miRNA-binding sites at the position normally cleaved by Argonaute 2, thereby enabling stable association of miRNA sponges with microribonucleoprotein complexes loaded with the corresponding miRNA. In addition, they specifically designed sponges with a complementary heptameric seed so that a single sponge can be used to effectively repress an entire miRNA seed family. These miRNA sponges can derepress miRNA targets as strongly as chemically modified AMOs in vitro. miRNA sponges have been applied to inhibit miRNA activity in Drosophila [97]. However, the efficacy of these stably expressed sponges in applications needs to be further evaluated.

4.3. miRNA Masking. A miRNA-mask is a gene-specific strategy developed by Xiao et al. (2007). miR-masks consist of single-stranded 2' -O-methyl-modified antisense oligonucleotides that are fully complementary to predicted miRNA binding sites in the $3^{\prime}$-UTR of the target mRNA. These modified oligonucleotides can form complementary duplex fragments with the target mRNA with higher affinity. In this study, Xiao and colleagues designed miR-masks complementary to HCN2 and HCN4 mRNA to prevent the repressive actions of miR-1 and miR-133 on protein expression of these genes [98]. The disadvantage of this gene-specific strategy is the limited scope (one target) for therapeutic purposes.

4.4. Restoring Tumor Suppressor miRNA Expression. For TS-miRs, which promote cancer when downregulated, small synthetic oligonucleotides that mimic endogenous mature miRNA molecules (designated miRNA mimics) restore expression of TS-miRs, thereby inducing cell death and blocking proliferation $[99,100]$. The concept of miRNA replacement therapy is perhaps best exemplified by the let-7 miRNA family. Let-7 is underexpressed in nonsmall cell lung cancer relative to normal lung tissue, which inversely correlates with the expression of the Ras oncoprotein, suggesting that let-7 negatively regulates the Ras oncoprotein 
[101]. In addition, let-7 expression is downregulated in other cancer types such as hepatocellular carcinoma, melanoma, and nasopharyngeal carcinoma. Let- 7 acts by suppressing protein expression of several genes such as high mobility group AT-hook 2 (HMGA2), Myc, CCND1, and BCL2-like 1 (BCL-XL) [102-106]. Functional studies using cultured lung cancer cells and mouse models of lung cancer have shown that administration of let-7 mimics blocks the proliferation of cancer cells and reduces the growth of lung tumors, respectively [107-109]. Moreover, in hepatocellular carcinoma cells, the transfection of a let-7 family member, let- $7 \mathrm{~g}$ mimics, inhibits cell proliferation by downregulating the oncogene, $\mathrm{c}-\mathrm{Myc}$, and upregulating the tumor suppressor gene, p16 $6^{\mathrm{INK} 4 \mathrm{~A}}[110]$. miRNA replacement is also demonstrated by miR-34a [111], which is underexpressed in multiple cancer types. miR-34a, a key effector of the p53 signaling pathway, induces apoptosis, G2 arrest, and senescence in cancer cell lines by repressing the expression of direct targets, such as cyclin-dependent kinase 4 (CDK4), cyclin-dependent kinase 6 (CDK6), CCND1, SIRT1, cyclin E2 (CCNE2), E2F transcription factor 3 (E2F3), neuroblastoma-derived Myc (MYCN), and B-cell CLL/lymphoma 2 (BCL2) [42, 46, 112-114].

One of the major problems for the use of miRNAs as therapeutic molecules relates to the tissue-specific delivery and cellular uptake of sufficient amounts of synthetic oligonucleotides to achieve sustained target inhibition [115]. Consequently, strategies have been developed to deliver miRNA-based therapeutics, including viral and nonviral vector systems. Viral vector-systems have high gene transfer efficiency but have limitations due to their lack of tumortargeting capability and to residual viral elements that can be immunogenic, cytopathic, or recombinogenic. However, adenovirus-associated vectors (AAVs) do not integrate into the genome and are efficiently eliminated with minimal toxicity as shown in Phase I and Phase II clinical trials [13]. Furthermore, systemic administration of mir-26a using an AAV in an animal model of hepatocellular carcinoma results in apoptosis induction and significant protection from disease progression without toxicity [116]. On the other hand, nonviral vector systems include cationic liposomemediated, nanoparticle-mediated, and polymer-mediated gene transfer systems for in vivo human therapy [117-119].

\section{Conclusions}

miRNAs have an important role in tumor development, progression, chemosensitivity, and cellular senescence. A better understanding of the function of miRNAs is required for the development of novel therapies, such as restoring TS-miRs and targeting oncomirs with anti-miRNA technology.

\section{Acknowledgments}

This study was supported by the BBVA Foundation. M. E. LLeonart is an FIS investigator (CP03/00101). B. S-Sendra was awarded a fellowship from the "la Caixa" Foundation.

\section{References}

[1] B. N. Davis and A. Hata, "Regulation of microRNA biogenesis: a miRiad of mechanisms," Cell Communication and Signaling, vol. 7, no. 18, 2009.

[2] D. P. Bartel, "MicroRNAs: genomics, biogenesis, mechanism, and function," Cell, vol. 116, no. 2, pp. 281-297, 2004.

[3] E. P. Murchison and G. J. Hannon, "miRNAs on the move: miRNA biogenesis and the RNAi machinery," Current Opinion in Cell Biology, vol. 16, no. 3, pp. 223-229, 2004.

[4] S. Pfeffer, M. Zavolan, F. A. Grässer et al., "Identification of virus-encoded microRNAs," Science, vol. 304, no. 5671, pp. 734-736, 2004.

[5] B. P. Lewis, I. H. Shih, M. W. Jones-Rhoades, D. P. Bartel, and C. B. Burge, "Prediction of Mammalian MicroRNA Targets," Cell, vol. 115, no. 7, pp. 787-798, 2003.

[6] U. A. Ørom, F. C. Nielsen, and A. H. Lund, "MicroRNA10a Binds the $5^{\prime}$-UTR of Ribosomal Protein mRNAs and Enhances Their Translation," Molecular Cell, vol. 30, no. 4, pp. 460-471, 2008.

[7] I. Lee, S. S. Ajay, I. Y. Jong et al., "New class of microRNA targets containing simultaneous $5^{\prime}$-UTR and $3^{\prime}$-UTR interaction sites," Genome Research, vol. 19, no. 7, pp. 1175-1183, 2009.

[8] A. M. Eiring, J. G. Harb, P. Neviani et al., "miR-328 functions as an RNA decoy to modulate hnRNP E2 regulation of mRNA translation in leukemic blasts," Cell, vol. 140, no. 5, pp. 652-665, 2010.

[9] P. E. Blower, J. H. Chung, J. S. Verducci et al., "MicroRNAs modulate the chemosensitivity of tumor cells," Molecular Cancer Therapeutics, vol. 7, no. 1, pp. 1-9, 2008.

[10] M. V. Iorio and C. M. Croce, "MicroRNAs in cancer: small molecules with a huge impact," Journal of Clinical Oncology, vol. 27, no. 34, pp. 5848-5856, 2009.

[11] S. Volinia, G. A. Calin, C. G. Liu et al., "A microRNA expression signature of human solid tumors defines cancer gene targets," Proceedings of the National Academy of Sciences of the United States of America, vol. 103, no. 7, pp. 2257-2261, 2006.

[12] J. Lu, G. Getz, E. A. Miska et al., "MicroRNA expression profiles classify human cancers," Nature, vol. 435, no. 7043, pp. 834-838, 2005.

[13] R. Garzon, G. Marcucci, and C. M. Croce, "Targeting microRNAs in cancer: rationale, strategies and challenges," Nature Reviews Drug Discovery, vol. 9, no. 10, pp. 775-789, 2010.

[14] Y. Lee, M. Kim, J. Han et al., "MicroRNA genes are transcribed by RNA polymerase II," EMBO Journal, vol. 23, no. 20, pp. 4051-4060, 2004.

[15] G. M. Borchert, W. Lanier, and B. L. Davidson, "RNA polymerase III transcribes human microRNAs," Nature Structural and Molecular Biology, vol. 13, no. 12, pp. 1097-1101, 2006.

[16] Y. Lee, C. Ahn, J. Han et al., "The nuclear RNase III Drosha initiates microRNA processing," Nature, vol. 425, no. 6956, pp. 415-419, 2003.

[17] R. I. Gregory, K. P. Yan, G. Amuthan et al., "The Microprocessor complex mediates the genesis of microRNAs," Nature, vol. 432, no. 7014, pp. 235-240, 2004.

[18] J. Han, Y. Lee, K. H. Yeom, Y. K. Kim, H. Jin, and V. N. Kim, "The Drosha-DGCR8 complex in primary microRNA processing," Genes and Development, vol. 18, no. 24, pp. 3016-3027, 2004. 
[19] Y. Zeng and B. R. Cullen, "Efficient processing of primary microRNA hairpins by Drosha requires flanking nonstructured RNA sequences," The Journal of Biological Chemistry, vol. 280, no. 30, pp. 27595-27603, 2005.

[20] J. Han, Y. Lee, K. H. Yeom et al., "Molecular basis for the recognition of primary microRNAs by the drosha-DGCR8 complex," Cell, vol. 125, no. 5, pp. 887-901, 2006.

[21] R. Yi, Y. Qin, I. G. Macara, and B. R. Cullen, "Exportin5 mediates the nuclear export of pre-microRNAs and short hairpin RNAs," Genes and Development, vol. 17, no. 24, pp. 3011-3016, 2003.

[22] K. Okamura, J. W. Hagen, H. Duan, D. M. Tyler, and E. C. Lai, "The mirtron pathway generates microRNA-class regulatory RNAs in Drosophila," Cell, vol. 130, no. 1, pp. 89-100, 2007.

[23] J. G. Ruby, C. H. Jan, and D. P. Bartel, "Intronic microRNA precursors that bypass Drosha processing," Nature, vol. 448, no. 7149, pp. 83-86, 2007.

[24] E. Berezikov, W. J. Chung, J. Willis, E. Cuppen, and E. C. Lai, "Mammalian Mirtron Genes," Molecular Cell, vol. 28, no. 2, pp. 328-336, 2007.

[25] V. N. Kim, J. Han, and M. C. Siomi, "Biogenesis of small RNAs in animals," Nature Reviews Molecular Cell Biology, vol. 10, no. 2, pp. 126-139, 2009.

[26] T. P. Chendrimada, R. I. Gregory, E. Kumaraswamy et al., "TRBP recruits the Dicer complex to Ago2 for microRNA processing and gene silencing," Nature, vol. 436, no. 7051, pp. 740-744, 2005.

[27] A. D. Haase, L. Jaskiewicz, H. Zhang et al., "TRBP, a regulator of cellular PKR and HIV-1 virus expression, interacts with Dicer and functions in RNA silencing," EMBO Reports, vol. 6, no. 10, pp. 961-967, 2005.

[28] R. W. Carthew and E. J. Sontheimer, "Origins and Mechanisms of miRNAs and siRNAs," Cell, vol. 136, no. 4, pp. 642655, 2009.

[29] M. E. LLeonart, A. Artero-Castro, and H. Kondoh, "Senescence induction; a possible cancer therapy," Molecular Cancer, vol. 8, article 3, 2009.

[30] M. Collado and M. Serrano, "Senescence in tumours: evidence from mice and humans," Nature Reviews Cancer, vol. 10, no. 1, pp. 51-57, 2010.

[31] M. Serrano, A. W. Lin, M. E. McCurrach, D. Beach, and S. W. Lowe, "Oncogenic ras provokes premature cell senescence associated with accumulation of p53 and p16(INK4a)," Cell, vol. 88, no. 5, pp. 593-602, 1997.

[32] J. Campisi and F. D’Adda Di Fagagna, "Cellular senescence: when bad things happen to good cells," Nature Reviews Molecular Cell Biology, vol. 8, no. 9, pp. 729-740, 2007.

[33] C. J. Sherr and F. McCormick, "The RB and p53 pathways in cancer," Cancer Cell, vol. 2, no. 2, pp. 103-112, 2002.

[34] C. L. Olsen, B. Gardie, P. Yaswen, and M. R. Stampfer, "Raf1-induced growth arrest in human mammary epithelial cells is p16-independent and is overcome in immortal cells during conversion," Oncogene, vol. 21, no. 41, pp. 6328-6339, 2002.

[35] M. Collado, J. Gil, A. Efeyan et al., "Tumour biology: senescence in premalignant tumours," Nature, vol. 436, no. 7051, p. 642, 2005.

[36] M. Braig and C. A. Schmitt, "Oncogene-induced senescence: putting the brakes on tumor development," Cancer Research, vol. 66, no. 6, pp. 2881-2884, 2006.

[37] J. Campisi, "Senescent cells, tumor suppression, and organismal aging: good citizens, bad neighbors," Cell, vol. 120, no. 4, pp. 513-522, 2005.
[38] J. C. Jeyapalan, M. Ferreira, J. M. Sedivy, and U. Herbig, "Accumulation of senescent cells in mitotic tissue of aging primates," Mechanisms of Ageing and Development, vol. 128, no. 1, pp. 36-44, 2007.

[39] P. Castro, D. Giri, D. Lamb, and M. Ittmann, "Cellular senescence in the pathogenesis of benign prostatic hyperplasia," Prostate, vol. 55, no. 1, pp. 30-38, 2003.

[40] G. T. Bommer, I. Gerin, Y. Feng et al., "p53-mediated activation of miRNA34 candidate tumor-suppressor genes," Current Biology, vol. 17, no. 15, pp. 1298-1307, 2007.

[41] T. C. Chang, E. A. Wentzel, O. A. Kent et al., "Transactivation of miR-34a by p53 broadly influences gene expression and promotes apoptosis," Molecular Cell, vol. 26, no. 5, pp. 745752, 2007.

[42] H. Tazawa, N. Tsuchiya, M. Izumiya, and H. Nakagama, "Tumor-suppressive miR-34a induces senescence-like growth arrest through modulation of the E2F pathway in human colon cancer cells," Proceedings of the National Academy of Sciences of the United States of America, vol. 104, no. 39, pp. 15472-15477, 2007.

[43] M. Yamakuchi and C. J. Lowenstein, "MiR-34, SIRT1 and p53: the feedback loop," Cell Cycle, vol. 8, no. 5, pp. 712-715, 2009.

[44] N. R. Christoffersen, R. Shalgi, L. B. Frankel et al., "P53independent upregulation of miR-34a during oncogeneinduced senescence represses MYC," Cell Death and Differentiation, vol. 17, no. 2, pp. 236-245, 2010.

[45] E. Langley, M. Pearson, M. Faretta et al., "Human SIR2 deacetylates p53 and antagonizes PML/p53-induced cellular senescence," EMBO Journal, vol. 21, no. 10, pp. 2383-2396, 2002.

[46] C. Welch, Y. Chen, and R. L. Stallings, "MicroRNA-34a functions as a potential tumor suppressor by inducing apoptosis in neuroblastoma cells," Oncogene, vol. 26, no. 34, pp. 5017-5022, 2007.

[47] I. Martinez, D. Cazalla, L. L. Almstead, J. A. Steitz, and D. DiMaio, "miR-29 and miR-30 regulate B-Myb expression during cellular senescence," Proceedings of the National Academy of Sciences of the United States of America, vol. 108, no. 2, pp. 522-527, 2011.

[48] J. J. Zhao, J. Lin, T. Lwin et al., "MicroRNA expression profile and identification of miR-29 as a prognostic marker and pathogenetic factor by targeting CDK6 in mantle cell lymphoma," Blood, vol. 115, no. 13, pp. 2630-2639, 2010.

[49] M. Fabbri, R. Garzon, A. Cimmino et al., "MicroRNA29 family reverts aberrant methylation in lung cancer by targeting DNA methyltransferases 3A and 3B," Proceedings of the National Academy of Sciences of the United States of America, vol. 104, no. 40, pp. 15805-15810, 2007.

[50] A. Palamarchuk, A. Efanov, N. Nazaryan et al., "13q14 deletions in CLL involve cooperating tumor suppressors," Blood, vol. 115, no. 19, pp. 3916-3922, 2010.

[51] X. Zhong, N. Li, S. Liang, Q. Huang, G. Coukos, and L. Zhang, "Identification of microRNAs regulating reprogramming factor LIN28 in embryonic stem cells and cancer cells," The Journal of Biological Chemistry, vol. 285, no. 53, pp. 41961-41971, 2010.

[52] B. S. Marasa, S. Srikantan, J. L. Martindale et al., "MicroRNA profiling in human diploid fibroblasts uncovers miR-519 role in replicative senescence," Aging, vol. 2, no. 6, pp. 333-343, 2010. 
[53] E. J. Noonan, R. F. Place, S. Basak, D. Pookot, and L. C. $\mathrm{Li}$, "miR-449a causes Rb-dependent cell cycle arrest and senescence in prostate cancer cells," Oncotarget, vol. 1, no. 5, pp. 349-358, 2010.

[54] X. Yang, M. Feng, X. Jiang et al., "miR-449a and miR-449b are direct transcriptional targets of $\mathrm{E} 2 \mathrm{~F} 1$ and negatively regulate pRb-E2F1 activity through a feedback loop by targeting CDK6 and CDC25A," Genes and Development, vol. 23, no. 20, pp. 2388-2393, 2009.

[55] S. Venkataraman, I. Alimova, R. Fan, P. Harris, N. Foreman, and R. Vibhakar, "MicroRNA 128a increases intracellular ROS level by targeting Bmi-1 and inhibits medulloblastoma cancer cell growth by promoting senescence," PLoS ONE, vol. 5, no. 6, Article ID e10748, 2010.

[56] O. Slaby, R. Lakomy, P. Fadrus et al., "MicroRNA-181 family predicts response to concomitant chemoradiotherapy with temozolomide in glioblastoma patients," Neoplasma, vol. 57, no. 3, pp. 264-269, 2010.

[57] R. Garzon, M. Garofalo, M. P. Martelli et al., "Distinctive microRNA signature of acute myeloid leukemia bearing cytoplasmic mutated nucleophosmin," Proceedings of the National Academy of Sciences of the United States of America, vol. 105, no. 10, pp. 3945-3950, 2008.

[58] R. Menghini, V. Casagrande, M. Cardellini et al., "MicroRNA 217 modulates endothelial cell senescence via silent information regulator 1," Circulation, vol. 120, no. 15, pp. 1524-1532, 2009.

[59] W. G. Zhao, S. N. Yu, Z. H. Lu, Y. H. Ma, Y. M. Gu, and J. Chen, "The miR-217 microRNA functions as a potential tumor suppressor in pancreatic ductal adenocarcinoma by targeting KRAS," Carcinogenesis, vol. 31, no. 10, pp. 1726$1733,2010$.

[60] V. Borgdorff, M. E. Lleonart, C. L. Bishop et al., "Multiple microRNAs rescue from Ras-induced senescence by inhibiting p21 Waf1/Cip1," Oncogene, vol. 29, no. 15, pp. 22622271, 2010.

[61] P. M. Voorhoeve, C. le Sage, M. Schrier et al., "A genetic screen implicates miRNA-372 and miRNA-373 As oncogenes in testicular germ cell tumors," Cell, vol. 124, no. 6, pp. 11691181, 2006.

[62] W. J. Cho, J. M. Shin, J. S. Kim et al., "MiR-372 regulates cell cycle and apoptosis of ags human gastric cancer cell line through direct regulation of LATS2," Molecules and Cells, vol. 28, no. 6, pp. 521-527, 2009.

[63] K. H. Lee, Y. G. Goan, M. Hsiao et al., "MicroRNA-373 (miR373) post-transcriptionally regulates large tumor suppressor, homolog 2 (LATS2) and stimulates proliferation in human esophageal cancer," Experimental Cell Research, vol. 315, no. 15, pp. 2529-2538, 2009.

[64] J. Yu, K. Ohuchida, K. Mizumoto, H. Fujita, K. Nakata, and M. Tanaka, "MicroRNA miR-17-5p is overexpressed in pancreatic cancer, associated with a poor prognosis and involved in cancer cell proliferation and invasion," Cancer Biology and Therapy, vol. 10, no. 8, pp. 748-757, 2010.

[65] T. S. Wong, X. B. Liu, B. Y. H. Wong, R. W. M. Ng, A. P. W. Yuen, and W. I. Wei, "Mature miR-184 as potential oncogenic microRNA of squamous cell carcinoma of tongue," Clinical Cancer Research, vol. 14, no. 9, pp. 2588-2592, 2008.

[66] H. Li, C. Bian, L. Liao, J. Li, and R. C. Zhao, "miR-17-5p promotes human breast cancer cell migration and invasion through suppression of HBP1," Breast Cancer Research and Treatment, vol. 126, no. 3, pp. 565-575, 2010.
[67] F. Yang, Y. Yin, F. Wang et al., "miR-17-5p promotes migration of human hepatocellular carcinoma cells through the p38 mitogen-activated protein kinase-heat shock protein 27 pathway," Hepatology, vol. 51, no. 5, pp. 1614-1623, 2010.

[68] T. F. F. Chow, M. Mankaruos, A. Scorilas et al., "The miR-1792 cluster is over expressed in and has an oncogenic effect on renal cell carcinoma," Journal of Urology, vol. 183, no. 2, pp. 743-751, 2010.

[69] S. Takakura, N. Mitsutake, M. Nakashima et al., "Oncogenic role of miR-17-92 cluster in anaplastic thyroid cancer cells," Cancer Science, vol. 99, no. 6, pp. 1147-1154, 2008.

[70] K. W. Lai, K. X. Koh, M. Loh et al., "MicroRNA-130b regulates the tumour suppressor RUNX3 in gastric cancer," European Journal of Cancer, vol. 46, no. 8, pp. 1456-1463, 2010.

[71] B. S. Marasa, S. Srikantan, K. Masuda et al., "Increased MKK4 abundance with replicative senescence is linked to the joint reduction of multiple microRNAs," Science Signaling, vol. 2, no. 94, p. ra69, 2009.

[72] I. Satzger, A. Mattern, U. Kuettler et al., "MicroRNA-15b represents an independent prognostic parameter and is correlated with tumor cell proliferation and apoptosis in malignant melanoma," International Journal of Cancer, vol. 126, no. 11, pp. 2553-2562, 2010.

[73] L. Scapoli, A. Palmieri, L. Lo Muzio et al., "MicroRNA expression profiling of oral carcinoma identifies new markers of tumor progression," International Journal of Immunopathology and Pharmacology, vol. 23, no. 4, pp. 12291234, 2010.

[74] L. Zhangy, T. Dengy, X. Li et al., "microRNA-141 is involved in a nasopharyngeal carcinoma-related genes network," Carcinogenesis, vol. 31, no. 4, pp. 559-566, 2010.

[75] L. Poliseno, L. Pitto, M. Simili et al., "The proto-oncogene LRF is under post-transcriptional control of MiR-20a: implications for senescence," PLoS ONE, vol. 3, no. 7, Article ID e2542, 2008.

[76] L. Pitto, M. Rizzo, M. Simili et al., "miR-290 acts as a physiological effector of senescence in mouse embryo fibroblasts," Physiological Genomics, vol. 39, no. 3, pp. 210218, 2009.

[77] H. Liu, S. Deng, Z. Zhao et al., "Oct4 regulates the miR-302 cluster in P19 mouse embryonic carcinoma cells," Molecular Biology Reports, vol. 38, no. 3, pp. 2155-2160, 2011.

[78] R. D. Palmer, M. J. Murray, H. K. Saini et al., "Malignant germ cell tumors display common microRNA profiles resulting in global changes in expression of messenger RNA targets," Cancer Research, vol. 70, no. 7, pp. 2911-2923, 2010.

[79] L. López-Vicente, G. Armengol, B. Pons et al., "Regulation of replicative and stress-induced senescence by RSK4, which is down-regulated in human tumors," Clinical Cancer Research, vol. 15, no. 14, pp. 4546-4553, 2009.

[80] B. D. Chang, E. V. Broude, M. Dokmanovic et al., "A senescence-like phenotype distinguishes tumor cells that undergo terminal proliferation arrest after exposure to anticancer agents," Cancer Research, vol. 59, no. 15, pp. 37613767, 1999.

[81] J. A. Ewald, J. A. Desotelle, G. Wilding, and D. F. Jarrard, "Therapy-induced senescence in cancer," Journal of the National Cancer Institute, vol. 102, no. 20, pp. 1536-1546, 2010 . 
[82] A. Krtolica, S. Parrinello, S. Lockett, P. Y. Desprez, and J. Campisi, "Senescent fibroblasts promote epithelial cell growth and tumorigenesis: a link between cancer and aging," Proceedings of the National Academy of Sciences of the United States of America, vol. 98, no. 21, pp. 12072-12077, 2001.

[83] D. Bhaumik, G. K. Scott, S. Schokrpur et al., "MicroRNAs $\mathrm{miR}-146 \mathrm{a} / \mathrm{b}$ negatively modulate the senescence-associated inflammatory mediators IL-6 and IL-8," Aging, vol. 1, no. 4, pp. 402-411, 2009.

[84] J. Krützfeldt, N. Rajewsky, R. Braich et al., "Silencing of microRNAs in vivo with 'antagomirs," Nature, vol. 438, no. 7068, pp. 685-689, 2005.

[85] J. Stenvang and S. Kauppinen, "MicroRNAs as targets for antisense-based therapeutics," Expert Opinion on Biological Therapy, vol. 8, no. 1, pp. 59-81, 2008.

[86] I. A. Asangani, S. A. K. Rasheed, D. A. Nikolova et al., "MicroRNA-21 (miR-21) post-transcriptionally downregulates tumor suppressor Pdcd4 and stimulates invasion, intravasation and metastasis in colorectal cancer," Oncogene, vol. 27, no. 15, pp. 2128-2136, 2008.

[87] L. B. Frankel, N. R. Christoffersen, A. Jacobsen, M. Lindow, A. Krogh, and A. H. Lund, "Programmed cell death 4 (PDCD4) is an important functional target of the microRNA miR-21 in breast cancer cells," The Journal of Biological Chemistry, vol. 283, no. 2, pp. 1026-1033, 2008.

[88] Z. Lu, M. Liu, V. Stribinskis et al., "MicroRNA-21 promotes cell transformation by targeting the programmed cell death 4 gene," Oncogene, vol. 27, no. 31, pp. 4373-4379, 2008.

[89] S. Zhu, M. L. Si, H. Wu, and Y. Y. Mo, "MicroRNA-21 targets the tumor suppressor gene tropomyosin 1 (TPM1)," The Journal of Biological Chemistry, vol. 282, no. 19, pp. 1432814336, 2007.

[90] F. Meng, R. Henson, H. Wehbe-Janek, K. Ghoshal, S. T. Jacob, and T. Patel, "MicroRNA-21 regulates expression of the PTEN tumor suppressor gene in human hepatocellular cancer," Gastroenterology, vol. 133, no. 2, pp. 647-658, 2007.

[91] J. G. Zhang, J. J. Wang, F. Zhao, Q. Liu, K. Jiang, and G. H. Yang, "MicroRNA-21 (miR-21) represses tumor suppressor PTEN and promotes growth and invasion in non-small cell lung cancer (NSCLC)," Clinica Chimica Acta, vol. 411, no. 1112, pp. 846-852, 2010.

[92] E. C. Connolly, K. van Doorslaer, L. E. Rogler, and C. E. Rogler, "Overexpression of miR-21 promotes an in vitro metastatic phenotype by targeting the tumor suppressor RHOB," Molecular Cancer Research, vol. 8, no. 5, pp. 691$700,2010$.

[93] J. Zheng, H. Xue, T. Wang et al., "miR-21 downregulates the tumor suppressor P12CDK2AP1and stimulates cell proliferation and invasion," Journal of Cellular Biochemistry, vol. 112, no. 3, pp. 872-880, 2011.

[94] M. L. Si, S. Zhu, H. Wu, Z. Lu, F. Wu, and Y. Y. Mo, "miR21-mediated tumor growth," Oncogene, vol. 26, no. 19, pp. 2799-2803, 2007.

[95] Y. Lu, J. Xiao, H. Lin et al., "A single anti-microRNA antisense oligodeoxyribonucleotide (AMO) targeting multiple microRNAs offers an improved approach for microRNA interference," Nucleic Acids Research, vol. 37, no. 3, article e24, 2009.

[96] M. S. Ebert, J. R. Neilson, and P. A. Sharp, "MicroRNA sponges: competitive inhibitors of small RNAs in mammalian cells," Nature Methods, vol. 4, no. 9, pp. 721-726, 2007.
[97] C. M. Loya, C. S. Lu, D. Van Vactor, and T. A. Fulga, "Transgenic microRNA inhibition with spatiotemporal specificity in intact organisms," Nature Methods, vol. 6, no. 12, pp. 897903, 2009.

[98] J. Xiao, B. Yang, H. Lin, Y. Lu, X. Luo, and Z. Wang, "Novel approaches for gene-specific interference via manipulating actions of microRNAs: examination on the pacemaker channel genes HCN2 and HCN4," Journal of Cellular Physiology, vol. 212, no. 2, pp. 285-292, 2007.

[99] Y. Akao, Y. Nakagawa, and T. Naoe, "let-7 microRNA functions as a potential growth suppressor in human colon cancer cells," Biological and Pharmaceutical Bulletin, vol. 29, no. 5, pp. 903-906, 2006.

[100] Y. Xiong, J. H. Fang, J. P. Yun et al., "Effects of microrna29 on apoptosis, tumorigenicity, and prognosis of hepatocellular carcinoma," Hepatology, vol. 51, no. 3, pp. 836-845, 2010.

[101] S. M. Johnson, H. Grosshans, J. Shingara et al., "RAS is regulated by the let-7 microRNA family," Cell, vol. 120, no. 5, pp. 635-647, 2005.

[102] C. Mayr, M. T. Hemann, and D. P. Bartel, "Disrupting the pairing between let-7 and Hmga2 enhances oncogenic transformation," Science, vol. 315, no. 5818, pp. 1576-1579, 2007.

[103] D. W. Müller and A. K. Bosserhoff, "Integrin $\beta$ expression is regulated by let-7a miRNA in malignant melanoma," Oncogene, vol. 27, no. 52, pp. 6698-6706, 2008.

[104] J. Schultz, P. Lorenz, G. Gross, S. Ibrahim, and M. Kunz, "MicroRNA let-7b targets important cell cycle molecules in malignant melanoma cells and interferes with anchorageindependent growth," Cell Research, vol. 18, no. 5, pp. 549557, 2008.

[105] S. Shimizu, T. Takehara, H. Hikita et al., "The let-7 family of microRNAs inhibits Bcl-xL expression and potentiates sorafenib-induced apoptosis in human hepatocellular carcinoma," Journal of Hepatology, vol. 52, no. 5, pp. 698-704, 2010.

[106] T. S. Wong, O. Y. Man, C. M. Tsang et al., "MicroRNA let7 suppresses nasopharyngeal carcinoma cells proliferation through downregulating c-Myc expression," Journal of Cancer Research and Clinical Oncology, vol. 137, no. 3, pp. 415422, 2011.

[107] A. Esquela-Kerscher, P. Trang, J. F. Wiggins et al., "The let-7 microRNA reduces tumor growth in mouse models of lung cancer," Cell Cycle, vol. 7, no. 6, pp. 759-764, 2008.

[108] M. S. Kumar, S. J. Erkeland, R. E. Pester et al., "Suppression of non-small cell lung tumor development by the let-7 microRNA family," Proceedings of the National Academy of Sciences of the United States of America, vol. 105, no. 10, pp. 3903-3908, 2008.

[109] P. Trang, P. P. Medina, J. F. Wiggins et al., "Regression of murine lung tumors by the let-7 microRNA," Oncogene, vol. 29, no. 11, pp. 1580-1587, 2010.

[110] F. F. Lan, H. Wang, Y. C. Chen et al., "Hsa-let-7g inhibits proliferation of hepatocellular carcinoma cells by downregulation of c-Myc and upregulation of p16INK4A," International Journal of Cancer, vol. 128, no. 2, pp. 319-331, 2011.

[111] J. F. Wiggins, L. Ruffino, K. Kelnar et al., "Development of a lung cancer therapeutic based on the tumor suppressor microRNA-34," Cancer Research, vol. 70, no. 14, pp. 59235930, 2010.

[112] F. Sun, H. Fu, Q. Liu et al., "Downregulation of CCND1 and CDK6 by miR-34a induces cell cycle arrest," FEBS Letters, vol. 582, no. 10, pp. 1564-1568, 2008. 
[113] J. S. Wei, Y. K. Song, S. Durinck et al., "The MYCN oncogene is a direct target of miR-34a," Oncogene, vol. 27, no. 39, pp. 5204-5213, 2008.

[114] M. Yamakuchi, M. Ferlito, and C. J. Lowenstein, "miR-34a repression of SIRT1 regulates apoptosis," Proceedings of the National Academy of Sciences of the United States of America, vol. 105, no. 36, pp. 13421-13426, 2008.

[115] L. Aagaard and J. J. Rossi, "RNAi therapeutics: principles, prospects and challenges," Advanced Drug Delivery Reviews, vol. 59, no. 2-3, pp. 75-86, 2007.

[116] J. Kota, R. R. Chivukula, K. A. O’Donnell et al., “Therapeutic microRNA delivery suppresses tumorigenesis in a murine liver Cancer Model," Cell, vol. 137, no. 6, pp. 1005-1017, 2009.

[117] T. V. Chirila, P. E. Rakoczy, K. L. Garrett, X. Lou, and I. J. Constable, "The use of synthetic polymers for delivery of therapeutic antisense oligodeoxynucleotides," Biomaterials, vol. 23, no. 2, pp. 321-342, 2002.

[118] N. L. Rosi, D. A. Giljohann, C. S. Thaxton, A. K.R. LyttonJean, M. S. Han, and C. A. Mirkin, "Oligonucleotidemodified gold nanoparticles for infracellular gene regulation," Science, vol. 312, no. 5776, pp. 1027-1030, 2006.

[119] I. S. Zuhorn, J. B. F. N. Engberts, and D. Hoekstra, "Gene delivery by cationic lipid vectors: overcoming cellular barriers," European Biophysics Journal, vol. 36, no. 4-5, pp. 349-362, 2007. 


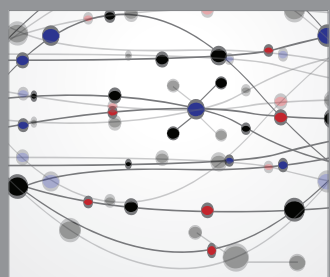

The Scientific World Journal
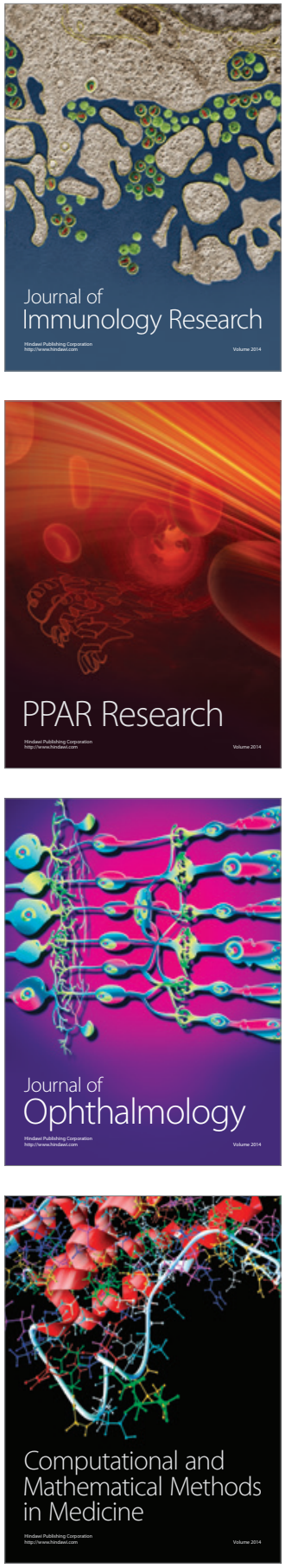

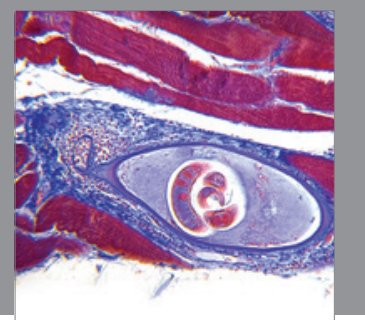

Gastroenterology

Research and Practice
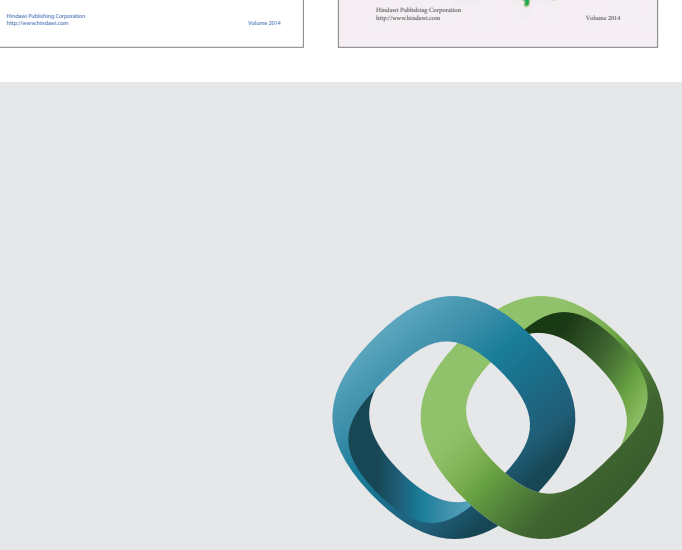

\section{Hindawi}

Submit your manuscripts at

http://www.hindawi.com
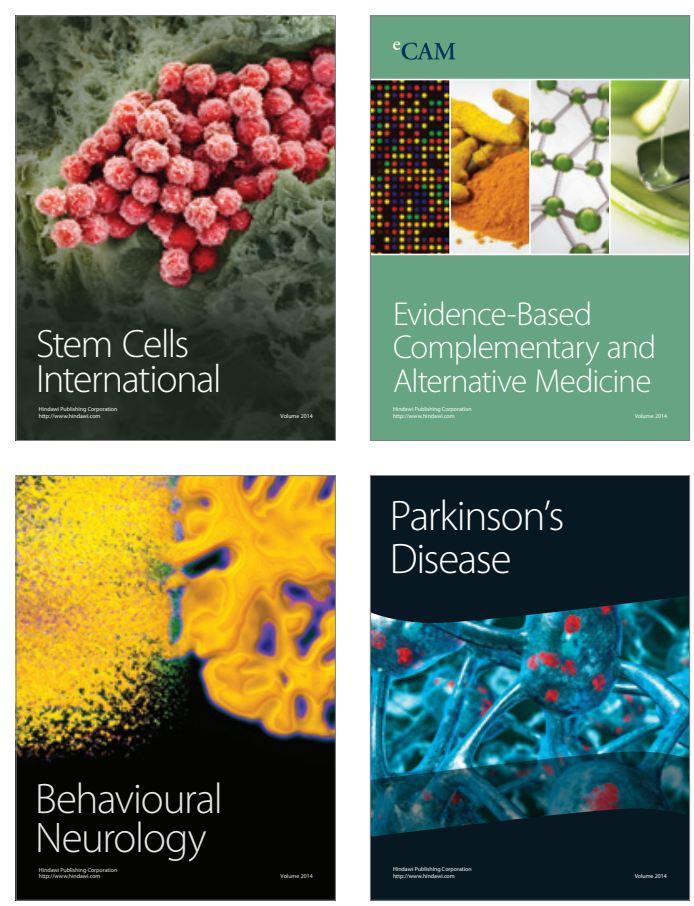

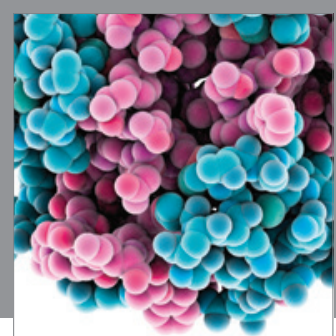

Journal of
Diabetes Research

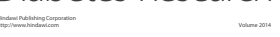

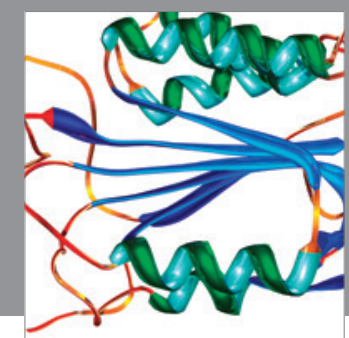

Disease Markers
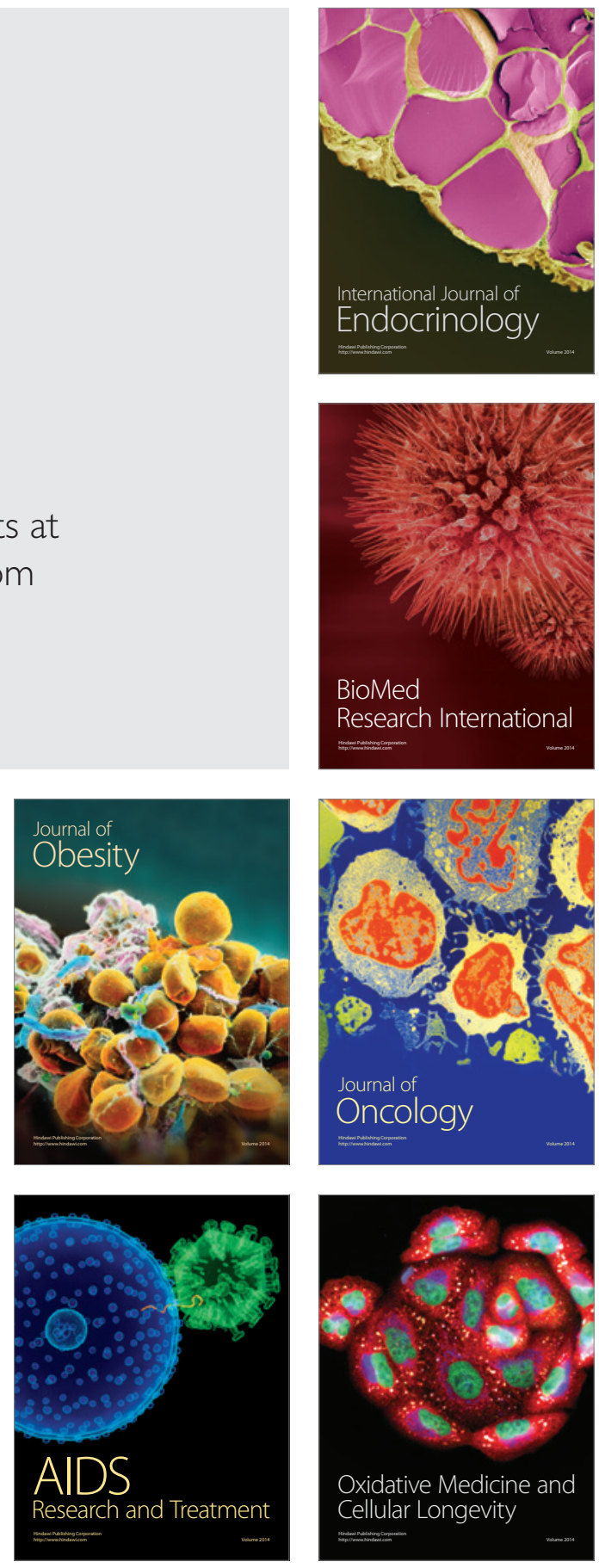